\title{
Research on Online Learning How to Change the Higher Education
}

\author{
Yong Luo \\ College of Science \\ National University of Defense Technology \\ Changsha, Hunan, China \\ Xiao Xiao \\ Chinese University MOOC \\ Beijing, China
}

\author{
Jianping $\mathrm{Li}^{*}$ \\ College of Science \\ National University of Defense Technology \\ Changsha, Hunan, China \\ *Corresponding author \\ Xiao Wang \\ College of Science \\ National University of Defense Technology \\ Changsha, Hunan, China
}

\begin{abstract}
With the development of network technology, the educational model has changed. Learners can access higher education resources and study courses online. This paper summarizes the trends in future education and assesses the impact of online learning on university education. We believe that university and classroom teaching models will not be replaced by online learning. Online learning can play an important role in pre-service teacher training. The research should help people understand higher education under the impact of online learning and the direction of higher education development.
\end{abstract}

Keywords-Online learning; higher education; classroom teaching

\section{INTRODUCTION}

The Internet makes communication so simple, online education[1] is bound to have an impact on university education. Many people have questions: What changes will happen in higher education in the future? Is there a need for university and classroom?

The education revolution is triggered by the transformation of educational technology. As information technology is more widely used in education, higher education is changing. The educational goal is shifting towards capacity building. Mixed learning[2] is more common, and student development will be more personalized. Learning is more student-centered, and lifelong learning will become a way of life for people.

Education and scientific exploration have deepened human understanding of nature. The new educational model accelerates the speed at which humans learn to master knowledge, allowing learners to have more time and energy to explore the unknown.

This study was funded by The 13th Five-Year Plan for Education Science in Hunan Province (grant number XJK18CXX010).

This study was funded by the Hunan Province Teaching Reform Research Project (grant number [2018]436).

This study was funded by Open Fund of University Mathematics Teaching Research and Development Center (CMC20190305).

This study was funded by Hunan Province Postgraduate Teaching Reform Project (grant number [2019]98).
We can look to the future education model based on the current state of education, educational technology, educational facilities and population development.

This paper presents some trends in the future development of education. Through online and offline mixed teaching practices and research, we find that universities should always focus on classroom teaching. Online learning can be an important aid to university education. It can enhance the breadth of education and the quality of teachers. These studies can help understand online education and identify the direction of higher education reform.

\section{TRENDS IN EDUCATION DEVELOPMENT}

Although there are many unpredictable factors in the development of education[3], there are four characteristics that are certainly foreseeable. They are education equality, shortage of educational resources; college education is affected by online education and educational technology to enhance the learning experience.

\section{A. Educational equality}

With the improvement of educational facilities, people's need for equality in education is becoming more and more urgent. From vocational education to higher education, everyone has equal access to education. Online education and distance education degrees are recognized, and online education begins to gradually occupy the in-service education market worldwide. At present, some countries have begun to implement the identification of long-distance master's degrees, and a large number of in-service learners with undergraduate degrees have obtained master's degrees through distance education.

Future distance education will enable everyone to enjoy the right to higher education. By setting up an online university major and a corresponding course group, learners can earn a university degree without having to step into a university 
campus. And with the increase of social recognition, learners will benefit from employment and work.

\section{B. Shortage of educational resources}

It is difficult for traditional educational resources to keep up with the development of science and technology. Under the global competition, many college graduates have found that the gap between the knowledge and skills and employment skills of the university is obvious. On the other hand, in some fast-growing industries, there is a shortage of talent. The reason is that talent training has not kept up with the development of the industry. Traditional educational resources are slow to update and slow to promote.

With the continuous development of virtual reality technology and network technology, new educational resources can efficiently cultivate job skills and adapt to the needs of fast-growing industries. Competitive competition education needs to adapt to the needs of the post more quickly and solve the contradiction between the supply and demand of talents. Job requirements have led to new demands for education and training and to a large extent the needs of non-school students, and online learning and online course degree acquisition will bring a lot of demand.

\section{College education is affected by online education}

Entity education is difficult to meet the needs of the future society for education and learning because of resources and costs. As network certification is recognized, more people will choose online courses to improve themselves. Of course, all teaching resources are derived from people, and physical education is always the provider of networked educational resources. The impact of online education does not mean that college education should not share educational resources. It should be used as an extension and extension of college education. It is foreseeable that future educational competition is likely to come from the competition in the field of online education.

\section{Educational technology to enhance the learning experience}

Networking has penetrated every level of society. The development of hardware technology has led to the emergence of types of network terminals. At the same time, it also makes the network more and more closely connected with human life. Portable devices such as mobile phones and mobile computers enable learners to learn everywhere and use the fragmented time to learn.

As the interface and means are improved, the learning experience of learners is also increasing. More people are willing to search and query knowledge through the Internet. The vast amount of knowledge resources help learners keep up with the continuous development of technology.

\section{CLASSROOM TEACHING WILL NOT BE REPLACED}

Classroom teaching[4] refers to the teacher's use of certain teaching theories, skills, means and methods in a given time and space according to the predetermined teaching plan, to teach the class students a certain content of teaching, talking, counseling and answering operation demonstration.

In the 16th century, class teaching attempts were made in classical middle schools founded in some countries in Western Europe. Some schools in Europe practice class teaching; the monthly and weekly textbook content and daily timetable are also specified in the charter. Therefore, classroom teaching emerged, and at the same time greatly promoted the progress and development of education.

Classroom is the field where students grow and the place to learn. In teaching, it is necessary to create the necessary situations according to the actual teaching, and provide students with opportunities for in-class practice. Let students practice in a specific environment so that they can understand the truth, experience emotions, and regulate behavior in the activities.

Classroom teaching is required to require teachers to be responsible for the whole class. At the same time, they are taught in accordance with their aptitude, supplemented by group teaching and individual teaching, so that all students can develop. There are four main advantages to classroom teaching.

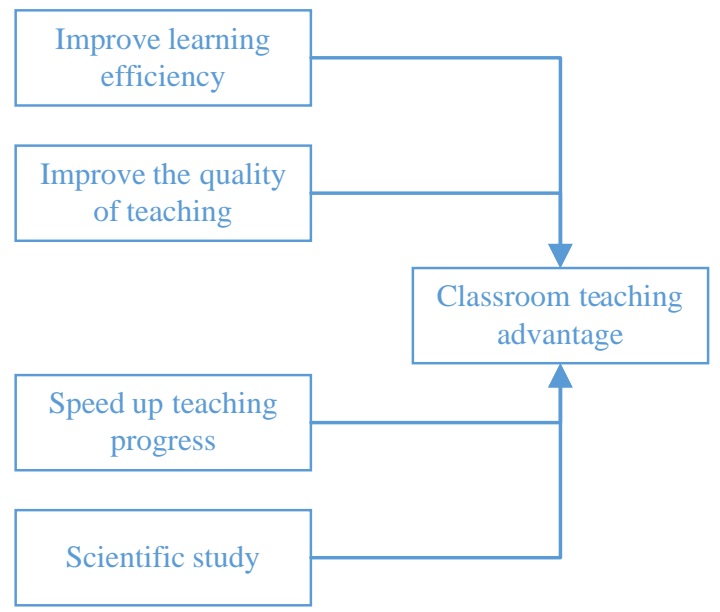

Fig.1. Classroom teaching advantage

(A)Students with the same or similar age and level of knowledge are grouped together to promote and enhance learning outcomes.

(B)Teachers simultaneously teach dozens of students according to a fixed schedule, expand the educational objects, speed up the teaching progress, and improve the efficiency of teaching.

(C)There are unified regulations and requirements in terms of content and time, so that teaching can be carried out in a planned and organized manner, which is conducive to improving the quality of teaching.

(D)Each subject alternately attends classes, which not only expands the knowledge area of students, but also enhances learning interests and effects, and reduces learning fatigue.

Classroom teaching also has certain limitations. It is not able to fully adapt to individual differences of students and take care of each student's interests, hobbies and specialties. At the same 
time, it is difficult to fully take care of the learning and development of excellent and poor students.

Due to the development of science and technology, the need to cultivate talents, in order to overcome the shortcomings of classroom teaching, adapt to individual differences of students, there have been organizational forms such as group teaching and even individual teaching. However, group teaching or graded teaching also brings many problems, such as psychologically adverse effects on different types of students, especially poor students. In addition, personalized instruction and personalized teaching are also affected by the size of the classroom.

Online learning enables convenient communication, which can overcome the shortcomings of traditional classroom teaching. However, if the learner is alone and outside of any team, it will become lazy and conservative. Although the development of network and information technology has increased the ability of people to interact with each other, the interpersonal relationship between classroom teaching and socialization will enable learners with similar knowledge levels and similar knowledge needs to form a learning team. In such a team, learners will have higher initiative, enthusiasm and consciousness.

Our research found that students on campus are also using online learning without class. The pass rate is only about $15 \%$, which is much lower than the normal classroom teaching. Therefore, it is the organization form of classroom teaching that allows students to master the most knowledge in the shortest time. Moreover, pre-class preparation, after-school exercises and assessment of a complete set of learning modules to achieve the best learning results.

Most of the knowledge of college students comes from extracurricular reading, self-study, and discussion with classmates, but most of these learning behaviors occur on campus. It is the environment of the school, the concentrated learning of the classroom and the teaching of the teachers that enable students to discover knowledge outside the classroom and find their own knowledge defects, thus enhancing their own learning. Human group learning behavior promotes the formation of cooperation. If learners want to learn from the Internet, it is very difficult. Students must be in a group. It is very difficult for learners who are in separate classes to complete the course.

It was the classmates in the class who made themselves overcome the inertia of learning and inspired the inspiration to gain knowledge. University students are an innovative group, and when these people are together, they can spark a spark of wisdom. When students enter the university and enter the classroom, the teacher's goal is to let them stand on the shoulders of giants, which will naturally inspire students to overcome difficulties and challenge the unknown courage. The university is to train students with a wide range of knowledge but a high level of research in one aspect.

Therefore, we should put university classroom teaching in the first place. Promote teaching exchanges and promote the level of curriculum construction in the process of building curriculum, and explore online and offline fusion teaching mode around classroom teaching reform. What changes is only the form of the classroom, and the same is the mode of classroom teaching. All college education reforms are based on 45 minutes of student time and self-study time outside of class. Under the current technical and training requirements, classrooms and university campuses are still the main forms of university education and the main channel for educating people.

\section{InNOVATIVE MODEL IN THE CONTEXT OF ONLINE EDUCATION}

The definition of innovation capability[5] refers to the ability to continuously provide new ideas, new theories, new methods and new inventions with economic, social and ecological values in the fields of technology and various practical activities. The definition of this innovative ability is considered to be narrow. We believe that the ability to innovate is the ability to solve unknown problems.

The ability to solve an unknown problem is something that everyone should have. This ability does not depend on the level of knowledge. When a person is knowledgeable, he can solve more problems than most people with relatively low levels of knowledge. However, this problem-solving has nothing to do with innovation. Extensive knowledge can help to screen out unrealistic ideas, but it can also bury those great real creations. But no matter which kind of innovation is produced, it is inseparable from thinking and discussion. Therefore, communication has become the best stage for generating and demonstrating ideas.

By analyzing the process of innovation, we find that communication between students and students is often the source of original results and the best way to improve their ability to innovate. In many cases, the teacher's guiding ability helps students understand the problem correctly, but in the process of solving the problem, the teacher should be a listener and cannot easily deny the student's thoughts. Even if it is not correct or does not work, let the students verify the conclusions themselves. This is the practice of innovation. Through specific practices, they can truly master the innovative approach.

Under the online education model, learners can break through the limitations of time and space to form a larger learning group and a broader knowledge group. But this kind of online communication is not as revolutionary as people have been. Analyzing the data of the online education platform forum, we can find that most learners are not suitable for such communication.

\section{A. The input mode of the interactive interface is inefficient.}

Although computers, networks, and human-computer interaction devices have been greatly developed, they are still far from meeting the requirements for helping learners communicate. Currently, the biggest problem is that the input of mathematical formulas plagues learners. Currently, a more effective method is to upload photos to paper, but the communication efficiency is really low compared to 
face-to-face communication. Most learners are reluctant to spend time on online communication.

\section{B. There is a big difference between online communication and offline communication.}

The mode of online communication can be understood as a linear communication method, that is, questions and answers are sequentially performed. With face-to-face communication, everyone involved in the discussion can interrupt, ask questions, etc. at any time, making the discussion more efficient and solving problems faster.

Online communication often prevents students who participate in communication from expressing their opinions in a timely manner. The efficiency of analysis and discussion is very low. It is only possible to solve this problem by establishing parallel discussion modes and discussion rooms. It is believed that solving under the current technical conditions is not a big problem. Once such a discussion mode emerges, it may partially remove the obstacles of online discussion.

\section{Online Education Has Made It Possible to IMPROVE THE LEVEL OF TEACHERS}

Of course, many universities incorporate MOOC into their student development programs, which can improve the school's curriculum. At present, the most important learners of online courses in universities are students at school. However, this is very limited to the improvement of teaching. Many teachers are complaining that the quality of students is declining year by year. This is because the scale of enrollment in universities is constantly expanding and the average quality of students is bound to decline.

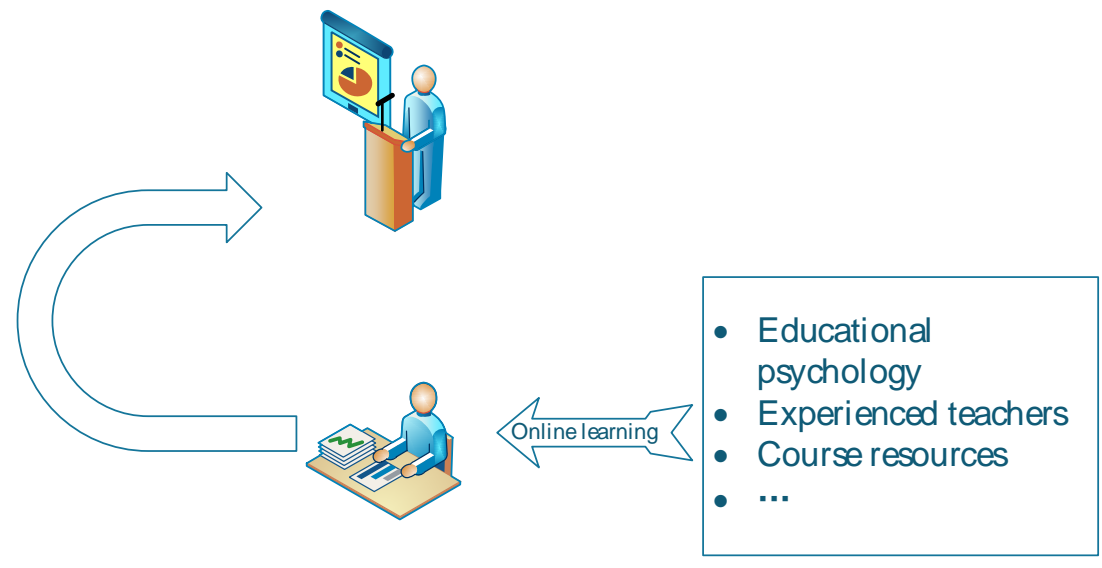

Fig.2. Use consulting resources for pre-job training

But the quality of teachers is also falling. Many old teachers need to be teaching assistants for 2-3 years before they can go to the podium, but now they only need to pass the test. Many school teachers, because of the expansion of enrollment, heavy teaching tasks[6], and did not have enough time to follow classes, the phenomenon of low teaching level is also widespread.

In addition, the specialty of the teacher's occupation requires an understanding of education, psychology, health psychology, etc., should understand the psychological characteristics, psychological confusion and psychological pressure of different students, in order to provide timely help and explanation and cultivate students' mental health quality. We can improve the quality of teachers by learning the corresponding courses online.

\section{CONCLUSION}

Although online learning can attract learners, it often fails to achieve quantitative learning. In the process of integrating online learning, universities should adhere to the classroom teaching and learning group model.

Online learning can increase the breadth of students' knowledge and serve as an important means of teacher training.
Therefore, the integration of school education and online learning is an important development direction for adapting to network technology.

\section{ACKNOWLEDGMENT}

This study was funded by The 13th Five-Year Plan for Education Science in Hunan Province (grant number XJK18CXX010).

This study was funded by the Hunan Province Teaching Reform Research Project (grant number [2018]436).

This study was funded by Open Fund of University Mathematics Teaching Research and Development Center (CMC20190305).

This study was funded by Hunan Province Postgraduate Teaching Reform Project (grant number [2019]98).

\section{REFERENCES}

[1] Mason R. Online education using learning objects[J]. British Journal of Educational Technology, 2004, 35(6):752-754. 
[2] Huang E Y, Lin S W, Huang T K. What type of learning style leads to online participation in the mixed-mode e-learning environment? A study of software usage instruction[J]. Computers \& Education, 2012, 58(1):338-349.

[3] Vodenko K V, Komissarova M A, Kulikov M M. Modernization of the Standards of Education and Personnel Training Due to Development of Industry 4.0 in the Conditions of Knowledge Economy's Formation[J]. 2019.
[4] ZHAO Xinyun, ZHOU Zhongqiang and WU Lamei et al. Short-Video Assisted Classroom Teaching in Organic Chemistry Laboratory[J]. University Chemistry, 2018, 33(3).

[5] Pongsathornwiwat A, Jeenanunta C, Huynh V N, et al. How collaborative routines improve dynamic innovation capability and performance in the tourism industry? A path-dependent learning model[J]. Asia Pacific Journal of Tourism Research, 2019, 24(4):281-295.

[6] Lowenthal P R, Nyland R, Jung E, et al. Does Class Size Matter? An Exploration into Faculty Perceptions of Teaching High-Enrollment Online Courses[J]. 2019. 